\title{
The Role of Ti and Lewis Acidity in Manganese Oxide Octahedral Molecular Sieves Impregnated with Titanium in Oxidation Reactions
}

\author{
Fitri Hayati, Sheela Chandren, Halimaton Hamdan, Hadi Nur* \\ Ibnu Sina Institute for Fundamental Science Studies, Universiti Teknologi Malaysia, 81310 UTM \\ Skudai, Johor, Malaysia
}

Received: 18th October 2013; Revised: 4th January 2014; Accepted: 4th January 2014

\begin{abstract}
Octahedral manganese oxide molecular sieves (OMS-2) was prepared by precipitation method and modified by impregnation of titanium with different titanium/manganese (Ti/Mn) ratio. It was discovered that Ti/Mn ratio of less than 0.5 still retains the original pure cryptomelane structure of OMS-2. However, for sample with Ti/Mn ratio of more than 0.5 , some rutile phases of titania $\left(\mathrm{TiO}_{2}\right)$ can be detected together with the cryptomelane phase. Lewis acid sites were also observed in the titanium modified OMS-2 (Ti-OMS-2). Ti-OMS-2 was then used as catalysts for the oxidation of cyclohexane, cyclohexene and styrene, where Ti-OMS-2 with Ti/Mn ratio of 0.67 was most active in all three of the oxidation reactions as compared to $\mathrm{TiO}_{2}$ and OMS-2. The results suggest that both titanium sites in framework and non-framework and the Lewis acidity created by the impregnation of Ti, increased the activity of OMS-2 in oxidation reactions. C2014 BCREC UNDIP. All rights reserved
\end{abstract}

Keywords: Titanium-impregnated manganese oxide molecular sieves; oxidation; Lewis acidity; framework and non-framework $\mathrm{Ti}$

How to Cite: Hayati, F., Chandren, S., Hamdan, H., Nur, H. (2014). The Role of Ti and Lewis Acidity in Manganese Oxide Octahedral Molecular Sieves Impregnated with Titanium in Oxidation Reactions. Bulletin of Chemical Reaction Engineering \& Catalysis, 9 (1): 28-38. (doi:10.9767/bcrec.9.1.5603.28-38)

Permalink/DOI: http://dx.doi.org/10.9767/bcrec.9.1.5603.28-38

\section{Introduction}

Octahedral manganese oxide molecular sieves (OMS-2) are synthetic manganese oxides which are made up of $\mathrm{MnO}_{6}$ octahedra, with a framework structure consisting of $2 \times 2$ type tunnels and also known as synthetic cryptomelane [1]. The tunnel size of this material is $4.6 \times 4.6$ $\AA$ and these materials are known to be inexpensive and easy to prepare as compared to other

* Corresponding Author.

E-mail: hadi@kimia.fs.utm.my (H. Nur),

Tel: +607-5536162, Fax: +607-5536080 manganese oxide type materials.

The usage of OMS-2 materials as catalysts in catalytic reactions has been explored in quite a few reactions, such as in the oxidation of benzyl alcohol [2,3]. Apart from that, OMS-2 materials also shown potential as electrocatalysts for the oxidation of methanol, for fuel cell applications [4] and also as active catalyst for the total oxidation of benzene and ethanol [5] and epoxidation of olefins [6,7]. The mild oxidants i.e. molecular oxygen and tert-butyl hydrogen peroxide (TBHP) used as oxidizing agents on OMS-2 materials have led to these materials being promising catalysts in fulfilling the environmental con- 
cern and regulations for clean environment.

In order to alter their structures and properties and to generate better electronic and catalytic performance, modification was done by doping cations into OMS-2 materials. These cations can substitute potassium and/or manganese ions which exist in the tunnel and framework structure, respectively [8]. The physical and chemical properties of doped OMS-2 are greatly influenced by the type, amount and location of the doping ions, where the properties of doped materials are significantly different from those of the undoped ones [9]. Among the transition metal doped OMS-2 materials, FeOMS-2 seems to be the best catalyst in some catalytic reactions such as oxidative dehydrogenation of 1-butene [10], oxidation of toluene [11], decomposition of the cyanine dye and pinacyanol chloride [12], and oxidative dehydrogenation of ethanol [13]. However the activity of Fe-OMS-2 is lower than that of Co-OMS-2 in the oxidation of styrene [6]. It suggests that the activity of metal doped OMS-2 also depends on the type of substrates involved in the reactions.

Titania $\left(\mathrm{TiO}_{2}\right)$ attracted much attention in catalysis as well as photocatalysis and it has been used in the synthesis of many chemical compounds. Titanium incorporated material shows outstanding catalytic properties, particularly in liquid phase oxidation process [14-16]. The discovery of titanium silicate-1 (TS-1) by Taramasso et al. [17] exhibited remarkable catalytic activity, selective epoxidations with 30\% aqueous hydrogen peroxide under very mild conditions, constituted a milestone in oxidation catalysis. The discovery of TS-1 led to the study on incorporation of titanium into porous materials: microporous material such as silicoaluminophosphate (SAPO-5) and aluminophosphates (AlPO-5, AlPO-11 and AlPO4-36) and mesoporous materials such as MCM-41 and MCM- 48 .

The incorporation of titanium into manganese oxide molecular sieve frameworks is feasible because of similar sizes, charges, and coordination tendencies of manganese and titanium cations. Ionic radii of octahedral $\mathrm{Mn}^{3+}, \mathrm{Mn}^{4+}$, and $\mathrm{Ti}^{4+}$ of $0.65 \AA, 0.53 \AA$ and $0.61 \AA$, respectively $[18,19]$ in crystals are close to one another. Hence $\mathrm{Ti}^{4+}$ can easily substitute either $\mathrm{Mn}^{3+}$ or $\mathrm{Mn}^{4+}$ without causing much structural disorder and serious charge imbalance. Due to the mixed-valence character of manganese in OMS2 , this material has distinct advantages over silicate, aluminosilicate and aluminophosphate molecular sieve materials in catalytic applications $[8,9]$.

In this work, a series of Ti-doped manganese oxide octahedral molecular sieves have been prepared. The structure of the catalysts was characterized by X-ray powder diffraction (XRD), X-ray photoelectron spectroscopy (XPS) and pyridine adsorption coupled with FTIR for acidity study. The effect of $\mathrm{Ti}$ on the performance of OMS-2 for oxidation of cyclohexane, cyclohexene and styrene was tested out and TiOMS- 2 with Ti/Mn ratio of 0.67 was most active when compared to $\mathrm{TiO}_{2}$ and OMS-2. The increase in the activity of OMS-2 in the oxidation reactions results indicates the important roles of titanium sites in framework and nonframework, and the Lewis acidity created by the impregnation of $\mathrm{Ti}$.

\section{Materials and Methods}

\subsection{Synthesis}

A precipitation method mentioned in [20] was used in the preparation of OMS-2. A mixture of a $1.75 \mathrm{M}$ solution of $\mathrm{MnSO}_{4} . \mathrm{H}_{2} \mathrm{O}(19.8 \mathrm{~g}$ in $67.5 \mathrm{ml}$ deionized water) and $6.8 \mathrm{ml}$ of concentrated $\mathrm{HNO}_{3}$ was firstly prepared. Subsequently, a $0.4 \mathrm{M}$ solution of $\mathrm{KMnO}_{4}$ (13.3 g in $225 \mathrm{ml}$ of deionized water) was added to the mixture, resulting the formation of black precipitate. This precipitate was first vigorously stirred and refluxed at $373 \mathrm{~K}$ for $24 \mathrm{~h}$, then filtered and washed with deionized water until neutral $\mathrm{pH}$ is achieved and dried at $393 \mathrm{~K}$. This process will then yield the OMS-2. The incorporation of titanium to give rise to Ti-OMS-2 involves the addition of a $\mathrm{KMnO}_{4}$ solution (13.3 g in $225 \mathrm{ml}$ of deionized water) to varying amounts of $\mathrm{Ti}_{2} \mathrm{SO}_{4}(25-75 \mathrm{ml})(15 \%(\mathrm{v} / \mathrm{v})$ in $\mathrm{H}_{2} \mathrm{SO}_{4}$ ), producing Ti-OMS-2 in the Ti/Mn ratio of $0.18,0.43$ and 0.67 . The mixture was then stirred, refluxed, filtered, washed, and dried following aforementioned procedure. Each of the samples was labelled as Ti-OMS-2 (0.18), Ti-OMS-2 (0.43) and Ti-OMS-2 (0.67), where the number in parentheses is the molar ratio of $\mathrm{Ti} / \mathrm{Mn}$.

\subsection{Characterization}

Each of the samples was subjected to characterization via powder XRD and phase content of the solid materials (Shimadzu XRD 6000 diffractometer with the CuKa $\lambda=1.5405 \AA$ radiation as the diffracted monochromatic beam at $30 \mathrm{kV}$ and $30 \mathrm{~mA}$ ). The elemental composition analysis of manganese and titanium in the sample was done by utilizing atomic absorption analysis (AAS). For this purpose, a PerkinElmer model Analyst 400 spectrophotometer was used. X-ray photoelectron spectra (XPS) were recorded using a Kratos XSAM-HIS 
(SAC) electron spectrometer fitted with a $\mathrm{Mg}$ $\mathrm{Ka}$ source. The anode was operated at $120 \mathrm{~W}$ $(12 \mathrm{kV}, 10 \mathrm{~mA})$ and the analyzer was operated at constant pass energy of $40 \mathrm{eV}$. The binding energy shifts due to surface charging were corrected using the $\mathrm{C} 1 \mathrm{~s}$ level at $284.6 \mathrm{eV}$. An absorbed base probe molecule was used to characterize the acidity of the solids. A wafer of the sample (10-12 mg) was locked in the cell equipped with $\mathrm{CaF}_{2}$ windows, and evacuated at $400{ }^{\circ} \mathrm{C}$ under vacuum condition for $4 \mathrm{~h}$. The introduction of pyridine as a probe molecule was then done into the evacuated sample at room temperature.

\subsection{Catalytic Oxidations}

\subsubsection{Oxidation of Cyclohexane}

The oxidation of cyclohexane was carried out at atmospheric pressure, as follows: $100 \mathrm{mg}$ of catalyst was suspended in a mixture of 27.8 mmol $(3 \mathrm{ml})$ of cyclohexane (Merck) and 10 mmol of TBHP ( $70 \%$ in water). The reaction mixture was heated under reflux with magnetic stirring in an oil bath at $333 \mathrm{~K}$. After the reaction, the catalyst was removed and gas chromatography coupled to mass spectrometry (GCMS, Agilent model G1540N, DB-1MS 20M capillary column) was used to identify the reaction products, which were quantified by gas chromatography (Trace GC) coupled to a flame ionization detector, using an internal standard (cyclooctane, Fluka) and calibration curves.

\subsubsection{Oxidation of Cyclohexene}

Cyclohexene (5 mmol), 70\% (wt. \%) TBHP in water $(10 \mathrm{mmol})$, catalyst $(50 \mathrm{mg})$, cyclooctane $(0.5 \mathrm{mmol})$ as internal standard and acetonitrile $(15 \mathrm{ml})$ as solvent were placed in a roundbottomed flask with a reflux condenser and the reaction was performed with stirring at $353 \mathrm{~K}$ in an oil bath for $24 \mathrm{~h}$. In order to evaluate qualitatively the reaction products, the GC-MS analysis technique was applied using Agilent model G1540N GC-MS instrument with HP$5 \mathrm{MS}$ capillary column (30 m x $0.25 \mathrm{~mm}$ ID, 0.25 $\mu \mathrm{m}$ film thickness). The analysis of products quantitatively is using Thermo Finnigan TraceGC instrument with Equity-1 capillary column (30 m x $0.25 \mathrm{~mm}$ ID, $0.25 \mu \mathrm{m}$ film thickness) and connected to FID detector.

\subsubsection{Oxidation of Styrene}

Styrene (5 mmol), 70\% (wt. \%) in water of TBHP $(10 \mathrm{mmol})$, catalyst $(50 \mathrm{mg})$ and acetonitrile $(15 \mathrm{ml})$ as solvent were placed in a roundbottomed flask with a reflux condenser and the reaction was performed with stirring at $343 \mathrm{~K}$ in an oil bath. The products were collected after $3 \mathrm{~h}$ of reaction and analyzed by GC and GCMS.

\section{Results and Discussion}

\subsection{Preparation and Characterization}

In our previous paper on the effect of different locations of titanium sites in Ti-OMS-2 [21], we made several findings based on the XRD patterns of OMS-2, Ti-OMS-2 (0.18) and Ti-OMS-2 (0.43). The samples are pure and exhibited high crystallinity, matching those of cryptomelane Q [22], consisting of 2 × 2 tunnels with a pore size of $4.6 \AA$, with double chains of edge-sharing and corner-sharing $\mathrm{MnO} 6$ octahedra, which is the natural counterpart of OMS-2 material [23] (Figure 1). Aside from the cryptomelane peaks, XRD patterns showed absence of other peaks, which highly suggests the successful incorporation of Ti into OMS-2. The intensities of the peaks at $2 \theta$ values of $30^{\circ}(310)$ and $38^{\circ}$ (211) also increased due to change in the aspect ratio of the cryptomelane fibers after $\mathrm{Ti}$ deposition, which showed that the preferred
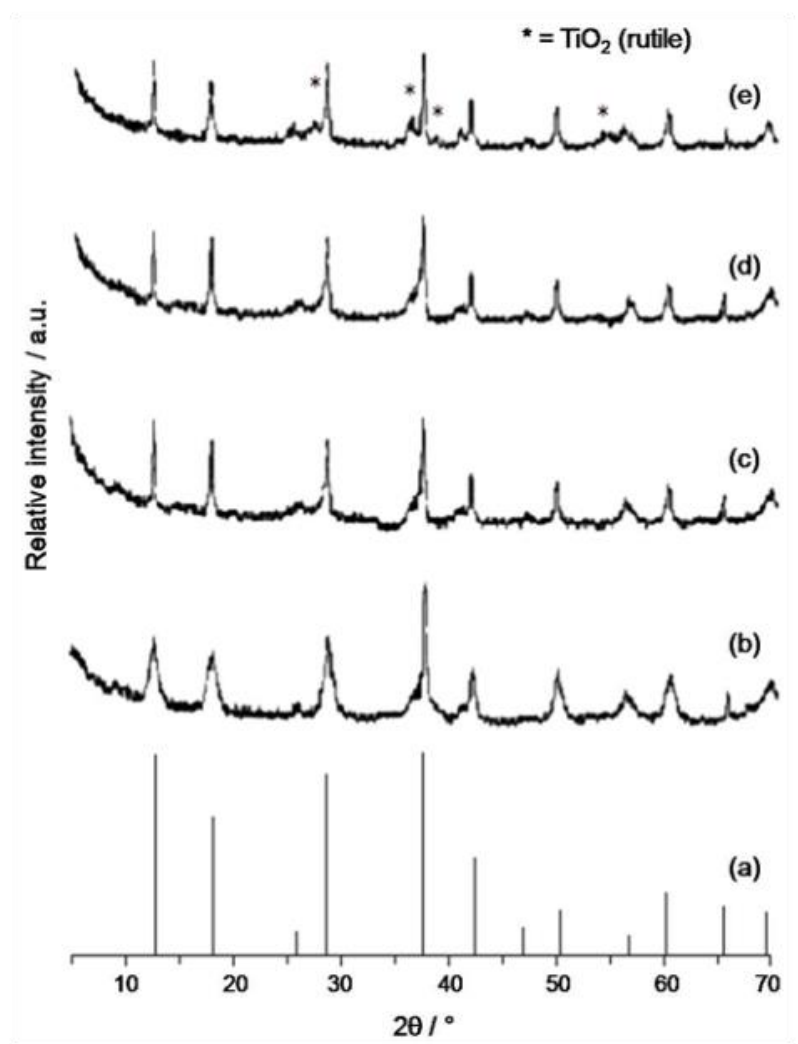

Figure 1. X-ray diffractograms of (a) cryptomelane (JCPDS 29, 102), (b) OMS-2, (c) Ti-OMS-2 (0.18), (d) Ti-OMS-2 (0.43) and (e) Ti-OMS-2 (0.67) 
orientation was achieved after modifications with Ti. Another observation that was made was the presence of the peaks of rutile phase for $\mathrm{TiO}_{2}$ at the ratio of $\mathrm{Ti}: \mathrm{Mn}$ higher than ca. 0.5 , which was not the case at the ratio of Ti:Mn less than ca. 0.5 (Figure 1). Considering the upper-limit of the titanium that could be incorporated into the framework, an early conclusion is that non-framework titanium species is formed when the Ti:Mn ratio reached 0.5. The amount of Ti located in non-framework is $25 \%$ in Ti-OMS (0.67), supported by the presence of rutile phase of $\mathrm{TiO}_{2}$ in Ti-OMS-2 (0.67) (Figure 1). XPS analyses were carried out in order to obtain information on the local chemical environments of manganese and titanium in cryptomelane from the variations in binding energies or chemical shifts of the photoelectron lines. As chemical shifts are very uniform among the photoelectron lines of an element, line separations rarely vary by more than $0.2 \mathrm{eV}$ [24]. A change in the separation of photoelectron lines suggests that a change in the local environment may have occurred. Line separation of binding energy of Mn $2 p$ and Ti $2 p$ and its differences between selected samples are listed in Table 1, while the Mn 2p XPS spectra of OMS2, Ti-OMS-2 (0.18 and Ti-OMS-2 (0.67) are shown in Figure 1. The binding energies for $\mathrm{Mn}$ $2 \mathrm{p} 1 / 2$ and Mn 2p3/2 peaks of all sample were about 654 and $642 \mathrm{eV}$, which are very close to those of $\mathrm{MnO}_{2} \mathrm{Mn} 2 \mathrm{p}$ peaks. The line separation for Mn $2 \mathrm{p} 1 / 2$ and $\mathrm{Mn} 2 \mathrm{p} 3 / 2$ peaks $\triangle \mathrm{BE}$ of OMS-2, Ti-OMS-2 (0.18) and Ti-OMS-2 (0.67) were $11.83,11.82$ and $11.91 \mathrm{eV}$, respectively. Difference of line separation $(\triangle \mathrm{BE})$ of Ti-OMS-2 (0.18) and $\triangle \mathrm{BE}$ of OMS-2 was $0.01 \mathrm{eV}$, which is very close to each other indicating that there is no change of the local environment of OMS-2 after the incorporation of titanium. For sample Ti-OMS-2 (0.67), the difference of line separa- tion was also lower than 0.2 indicating that no change in the local environment Mn 2p after the addition of titanium. This is in agreement with results by Cai et al. [24] which reported that the local environment of Mn 2p of FeOMS-2 did not show any significant changes although hematite phase was observed in that sample by using XRD. However, the binding energies of Mn 2p of OMS-2 are lower than that of Ti-OMS-2 (0.18) (Figure 2). This confirmed the substitution of some manganese by titanium in the framework of OMS-2. The assumption is supported by considering the binding strength on bridging oxygen atom in OMS-2 and Ti-OMS-2 as shown in Figure 3. Structures A, B, C represent pure OMS-2, Ti incorporated OMS-2 and $\mathrm{TiO}_{2}$, respectively. The binding strength of structure A, which is lower than of structure $\mathrm{B}$, indicates that $\mathrm{A}$ is less stable than $\mathrm{B}$, and consequently the binding energy of $\mathrm{Mn}$ in pure OMS-2 is lower than that in Ti-OMS-2 sample. As shown in Table 1, the separation of titanium $2 \mathrm{p} 1 / 2$ and $2 \mathrm{p} 3 / 2$ peaks $\Delta \mathrm{BE}$ increased from 5.36 to $5.64 \mathrm{eV}(\triangle \mathrm{BE}=0.28)$ when the titanium doping ratio increased from 0.18 to 0.67 . This indicates that the local environment of titanium in Ti-OMS-2 (0.18) is different from that of Ti-OMS-2 (0.67). The binding energy Ti $2 p$ of samples increases in the order of: Ti-OMS-2 (0.67) < TiO2-OMS-2 (0.18) (Figure 4) due to the difference in the local environment of each sample. The lowest binding energy of Ti-OMS-2 (0.18) caused by incorporation of titanium in the framework of OMS-2 (Structure B) which has total bond strength lower than Structure C (Figure 3). Ti-OMS-2 (0.67) has a significant difference in $\triangle \mathrm{BE}$ (more than $0.2 \mathrm{eV}$ ) indicating that it has both Structures $\mathrm{B}$ and $\mathrm{C}$ (titanium framework and nonframework exists in the sample). The oxidation state of the Ti species was also examined by X-

Table 1. Binding Energies (eV) of $\mathrm{Mn} 2 \mathrm{p}$, Ti 2p, its line separation ( $\triangle \mathrm{BE})$ and difference of line separation from selected samples

\begin{tabular}{|c|c|c|c|c|c|c|c|c|}
\hline & $\begin{array}{c}\mathrm{BE} \mathrm{Mn} \\
2 \mathrm{p}_{1 / 2}(\mathrm{eV})\end{array}$ & $\begin{array}{c}\text { BE Mn } \\
2 \mathrm{p}_{3 / 2}(\mathrm{eV})\end{array}$ & $\begin{array}{c}\Delta \mathrm{BE} \mathrm{Mn} 2 \mathrm{p} \\
(\mathrm{eV})\end{array}$ & $\begin{array}{c}\text { Difference } \\
\text { of } \triangle \mathrm{BE} \mathrm{Mn} \\
2 \mathrm{p} \text { of } \mathrm{X}^{\mathrm{a}} \text { and } \\
\text { OMS-2 }(\mathrm{eV})\end{array}$ & $\begin{array}{c}\mathrm{BE} \mathrm{Ti} \\
2 \mathrm{p}_{1 / 2}(\mathrm{eV})\end{array}$ & $\begin{array}{c}\mathrm{BE} \mathrm{Ti} \\
2 \mathrm{p}_{3 / 2}(\mathrm{eV})\end{array}$ & $\begin{array}{l}\Delta \mathrm{BE} \mathrm{Ti} \\
2 \mathrm{p}(\mathrm{eV})\end{array}$ & $\begin{array}{c}\text { Difference of } \\
\Delta \mathrm{BE} \text { Ti } 2 \mathrm{p} \text { of } \mathrm{Y}^{\mathrm{b}} \\
\text { and OMS-2 } \\
(\mathrm{eV})\end{array}$ \\
\hline OMS-2 & 653.18 & 641.75 & 11.83 & - & - & - & - & - \\
\hline $\begin{array}{l}\text { Ti-OMS-2 } \\
(0.18)\end{array}$ & 653.73 & 641.91 & 11.82 & 0.01 & 462.89 & 457.53 & 5.36 & - \\
\hline $\begin{array}{l}\text { Ti-OMS-2 } \\
(0.67)\end{array}$ & 653.88 & 641.97 & 11.91 & 0.08 & 463.56 & 457.92 & 5.64 & 0.28 \\
\hline
\end{tabular}

aX refers to Ti-OMS-2(0.18) and Ti-OMS-2(0.67); bY refers to Ti-OMS-2(0.67) 
ray photoelectron spectroscopy. Figure 4 shows the XPS of the materials in the Ti $2 \mathrm{p} 1 / 2$ and $\mathrm{Ti}$ $2 \mathrm{p} 3 / 2$ binding energy (BE) regions.

The Ti $2 \mathrm{p} 3 / 2$ peak is centred at 457.53 $458.17 \mathrm{eV}$, and the Ti $2 \mathrm{p} 1 / 2$ peak is found at 462.89-464.01 eV, with a spin energy separation of 5.36-5.84 eV. This is characteristic of $\mathrm{Ti}^{4+}[25,26]$. In particular, the peak position of $\mathrm{Ti}^{4+}$ is significantly influenced by its coordination environment, and the Ti 2p3/2 XPS peak of the octahedral coordinated $\mathrm{Ti}^{4+}$ is generally located at lower BE (about 457.5-458.3 eV), while that of tetrahedral coordinated $\mathrm{Ti}^{4+}$ at higher BE (about 458.5-463.4 eV). The observed BE Ti 2 p3/2 values are nearer to those observed for the octahedral coordinated $\mathrm{Ti}^{4+}$, indicating that the Ti species in Ti-OMS-2 materials are located at the octahedral coordinated environments.

IR spectrum of acidity study by pyridine adsorption after evacuation under vacuum at 400 ${ }^{\circ} \mathrm{C}$ and $150{ }^{\circ} \mathrm{C}$ are shown in Figure 5. No peaks were observed for OMS-2 (Figure 5 (a)) while Lewis acid sites are formed in Ti-OMS-2 (0.67) as indicated by the appearance of peaks at $1447 \mathrm{~cm}^{-1}, 1489 \mathrm{~cm}^{-1}$ and $1604 \mathrm{~cm}^{-1}$ (Figure 5 (b)). No Brönsted acid sites were detected in both of the samples, as proven by the absence of peaks at $1540 \mathrm{~cm}^{-1}$. The data indicates that the insertion of Ti into the framework of OMS2 created Lewis acids in the sample.

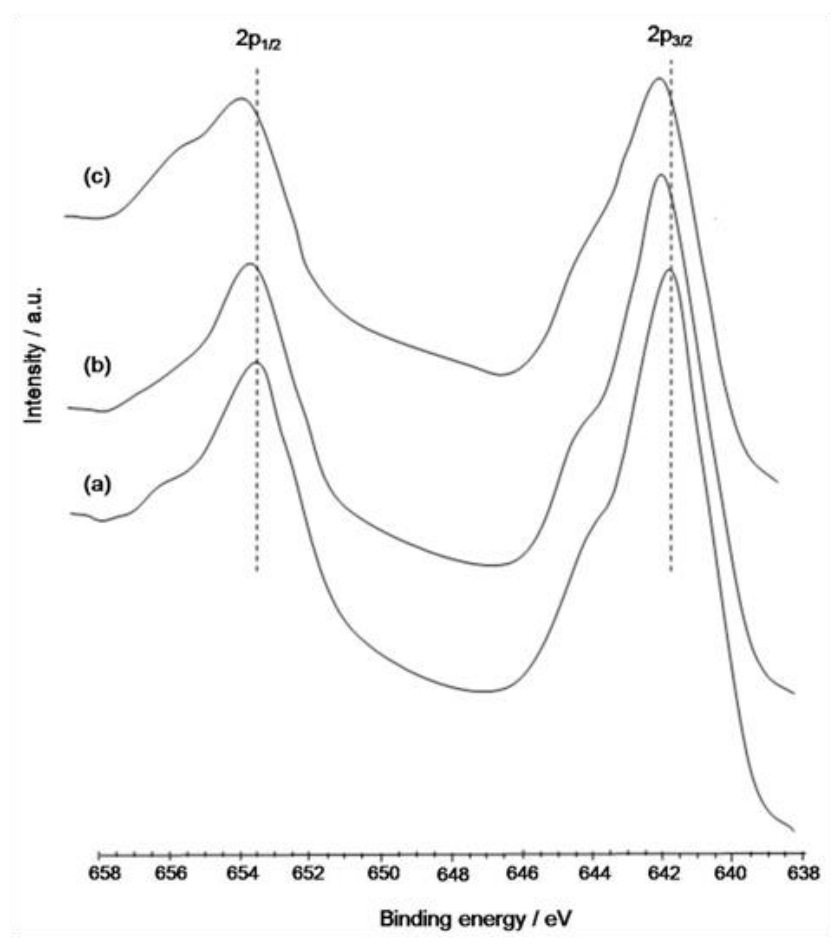

Figure 2. Detailed XPS spectra for the Mn $2 p$ transition of (a) OMS-2, (b) Ti-OMS-2 (0.18) and (c) Ti-OMS-2 (0.67). analysis.

\subsection{Catalytic Activity}

\subsubsection{Oxidation of Cyclohexane}

Oxidation of cyclohexane with TBHP under solvent-free condition was carried out by using OMS-2 and Ti-modified OMS-2 as catalysts. The main products observed after the reaction; detected by GC and GC-MS, are cyclohexanol and cyclohexanone (Figure 6). Cyclohexyl hydroperoxide as by-product was also observed. Cyclohexyl hydroperoxide was an intermediate which was converted to cyclohexanol and cyclohexanone [27-29]. Figure 6 also shows that in blank reaction condition, only cyclohexyl hydroperoxide was detected as the product. The absence of cyclohexanol and cyclohexanone in blank reaction indicates that catalyst was needed to decompose cyclohexyl hydroperoxide to cyclohexanol and cyclohexanone. As shown in Figure 6, no overoxidation products such as n-hexanal and adipic acid or the formation of cyclohexene were observed. This indicates that the catalysts were selective to cyclohexanol and cyclohexanone. The conversion and selectivity of cyclohexanol and cyclohexanone are in the range of $4.4-7.8$ and $89-92 \%$, respectively, which are higher than that of industrial process of about 4 and $75-85 \%$, respectively [30,31]. As shown in Figure 6 conversion of cyclohexane using OMS-2 as the catalyst was

\section{Configuration}

(A)

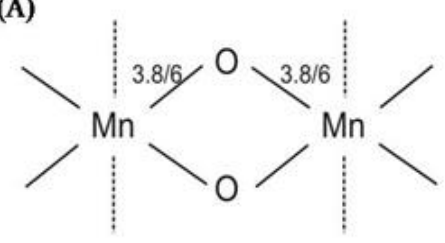

(B)<smiles>C[Y9]1(C)O[Ge](C)(C)O[13C]1(C)C</smiles>

(C)

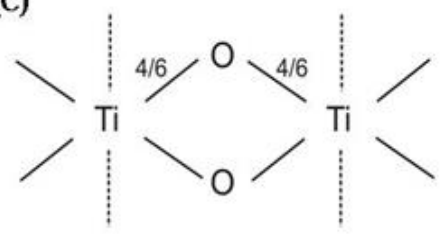

Figure 3. Bond strength on bridging oxygen atoms. 
lower than Ti-modified OMS-2. The highest conversion was obtained by Ti-OMS-2 (0.67). It suggested that the presence of non-framework $\mathrm{TiO}_{2}$ in the sample (as observed in XRD and XPS analyses) increases conversion of cyclohexane.

\subsubsection{Oxidation of Cyclohexene}

Oxidation of cyclohexene with TBHP as oxidant in acetonitrile as solvent was done over OMS-2, Ti-OMS-2 (0.18; 0.67$)$ and $\mathrm{TiO}_{2}$ rutile. $\mathrm{TiO}_{2}$ in rutile phase was used since this phase was observed as impurity in Ti-OMS-2 (0.67). The reaction was carried out at $343 \mathrm{~K}$ for $2 \mathrm{~h}$ and the products observed were epoxy cyclohexane, 2-cyclohexen-1-one and 2-cyclohexen-1-ol. The conversion of cyclohexene and selectivity towards 2-cyclohexen-1-one, 2-cyclohexen-1-ol and epoxycyclohexane as the reaction products are shown in Figure 7. As demonstrated, the reaction catalyzed by all the catalysts produced the highest yield of 2-cyclohexen-1-one and their selectivity towards the formation of products are almost similar to each other except for $\mathrm{TiO}_{2}$ rutile sample, as no epoxy cyclohexane was observed as product when $\mathrm{TiO}_{2}$ rutile was

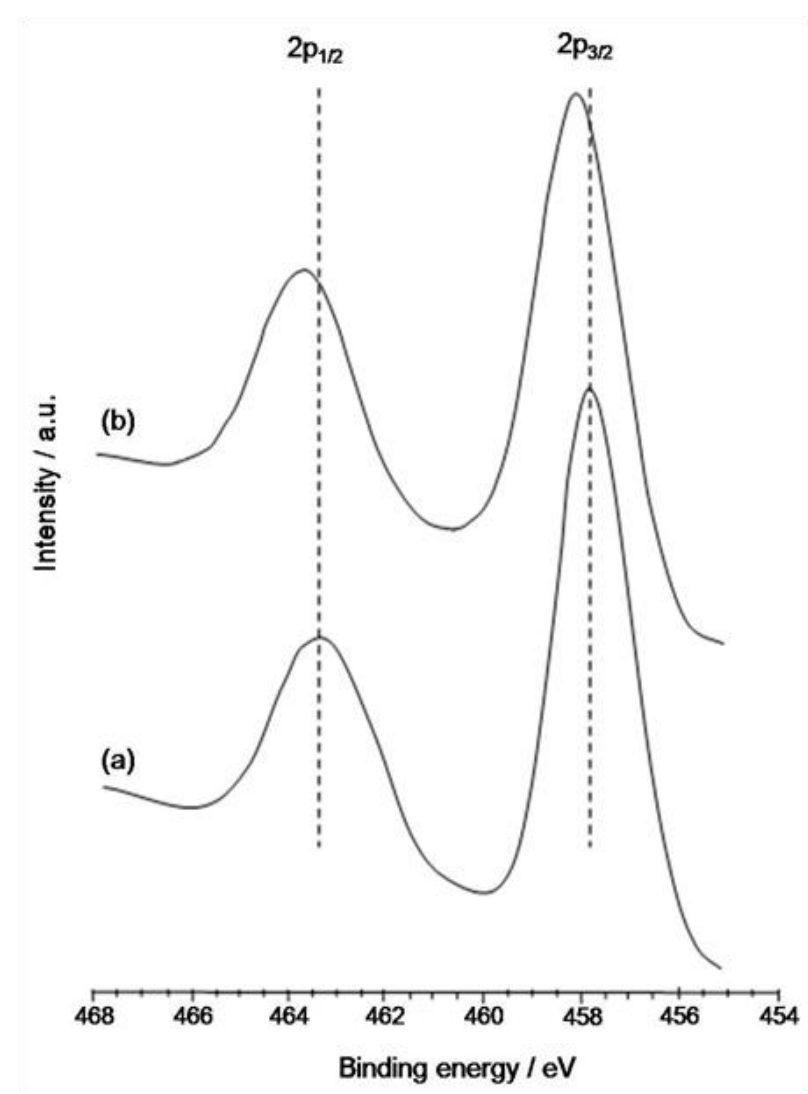

Figure 4. Detailed XPS spectra for the Ti $2 p$ transition of (a) Ti-OMS-2 (0.18) and (b) TiOMS-2 (0.67) used as the catalyst. From the figure it is also seen that the conversion of cyclohexene on TiOMS-2 (0.18) is significantly higher than that of OMS-2 catalyst. It was well evidenced that titanium incorporated OMS-2 enhanced the catalytic performance of OMS-2 catalyst which indicates that there is a synergetic effect of $\mathrm{Ti}$ and OMS-2 in Ti-OMS-2 catalyst. However, the most active was Ti-OMS-2 (0.67) catalyst, where the effect non-framework titanium active sites on OMS-2 material in the enhancement of its catalytic activity in the oxidation of

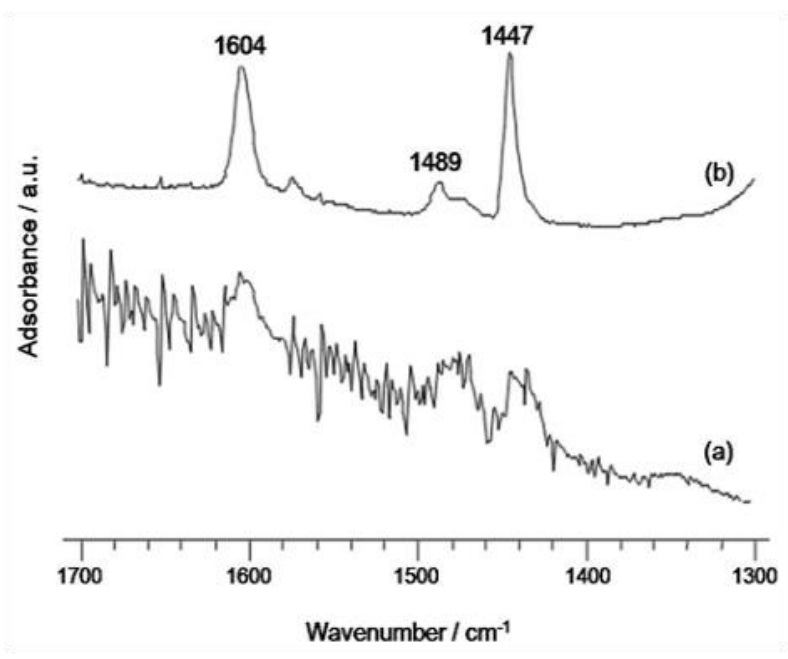

Figure 5. FTIR spectra of (a) OMS-2 and (b) Ti-OMS-2 (0.67) after evacuation under vacuum at $400{ }^{\circ} \mathrm{C}$ for $4 \mathrm{~h}$ followed by pyridine adsorption at room temperature and evacuation at $150^{\circ} \mathrm{C}$ for $1 \mathrm{~h}$

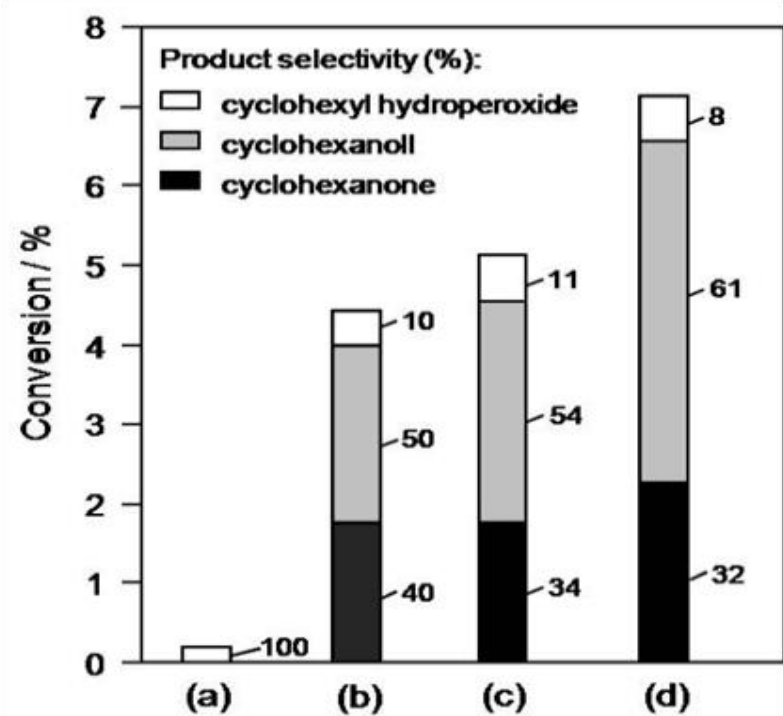

Figure 6. The conversion and product selectivity of the oxidation of cyclohexane with tertbutyl hydroperoxide (TBHP) using (a) blank, (b) OMS-2, (c) Ti-OMS-2 (0.05) and (d) Ti-OMS2 (0.67) as catalysts 
cyclohexene were significant. The formation of the allylic oxidation products 2-cyclohexene-1one and 2-cyclohexene-1-ol which was more dominant than epoxy cyclohexane shows the preferential attack of the activated $\mathrm{C}-\mathrm{H}$ bond over the $\mathrm{C}=\mathrm{C}$ bond [32]. TBHP as oxidant promoted the allylic oxidation pathway and epoxidation was minimized. This was also observed under alumina-supported with divalent and trivalent transition metal ions and complexes [3234].

\subsubsection{Oxidation of Styrene}

The reaction condition of styrene oxidation was similar to the oxidation of cyclohexene. The reaction was carried out at $343 \mathrm{~K}$ in oil bath using acetonitrile and TBHP as the solvent and oxidant, respectively. The products of this reaction are benzaldehyde, styrene oxide and phenylacetaldehyde. The oxidation products of styrene using TBHP as the oxidant catalyzed by $\mathrm{TiO}_{2}$ (rutile phase), OMS-2, and TiOMS-2 were analyzed by GC. The selectivity towards benzaldehyde, styrene oxide and phenylacetaldehyde as the reaction products is shown in Figure 8. The reaction catalyzed by all the catalysts produced the highest yield of benzaldehyde and their selectivities toward the formation of products are almost similar to each other. In our previous paper [21], TS-1 was used as a reference catalyst in this reaction. TS- 1 showed a high selectivity (52\%) towards benzaldehyde as opposed phenylacetaldehyde, which was the major product in the oxidation of styrene by TS-1 zeolite, while no styrene oxide was produced [35]. As the formation of phenylacetaldehyde requires the presence of Brönsted acid sites, the lack of these acid sites

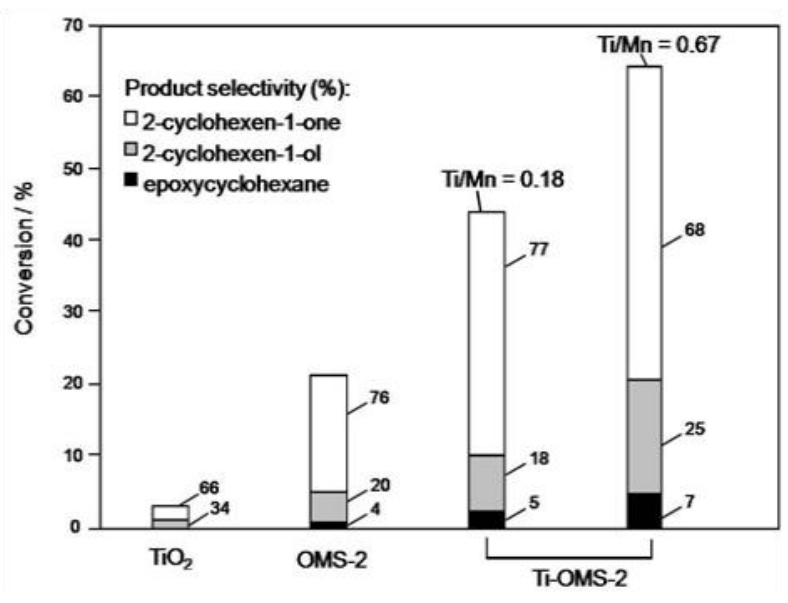

Figure 7. The conversion and product selectivity of the oxidation of cyclohexene with TBHP using different catalysts. in TS-1 resulted in higher selectivity towards benzaldehyde instead. As reported in section 3.1 , the acidity study by pyridine adsorption shows that Lewis acid sites were formed in TiOMS-2 (0.67) and no Lewis acids were observed for OMS-2 sample. This is the possible reason why $\mathrm{TiO}_{2}$ and OMS-2 catalysts are not selective towards phenylacetaldehyde. OMS-2 and $\mathrm{TiO}_{2}$ may have promoted the carbon-carbon bond cleavage, resulting in high selectivity towards the formation of benzaldehyde.

As shown in Figure 8, a considerable increase in the conversion of styrene over $\mathrm{Ti}$ OMS-2, OMS- 2 and $\mathrm{TiO}_{2}$ after $3 \mathrm{~h}$ of the reactions was clearly observed when Ti-OMS-2 (0.67) was used as catalyst. In our preceding paper [21], we discussed how this increase was caused by the presence of non-framework titanium species in Ti-OMS-2 (0.67). The superior performance of Ti-OMS-2 (0.67) strongly suggests the occurrence of synergetic effect of nonframework Ti with OMS-2. This was further supported by our findings from XRD and XPS analyses, and will be discussed in more detailed in the next sections.

\subsubsection{Effect of Lewis Acidity}

The analysis of acidity of Ti-OMS-2 (0.67) proved that the titanium site on OMS-2 caused increasing Lewis acidity of the catalyst. Table 2 shows the correlation between Lewis acidity and conversion of substrates in oxidation of cyclohexane, cyclohexene and styrene with TBHP as the oxidant. It shows that Ti-OMS-2 (0.67), which has strong Lewis acidity as compared to OMS-2, gave higher conversion in the oxidation of cyclohexane, cyclohexene and styrene. It indicated that Lewis acid played a role in the en-

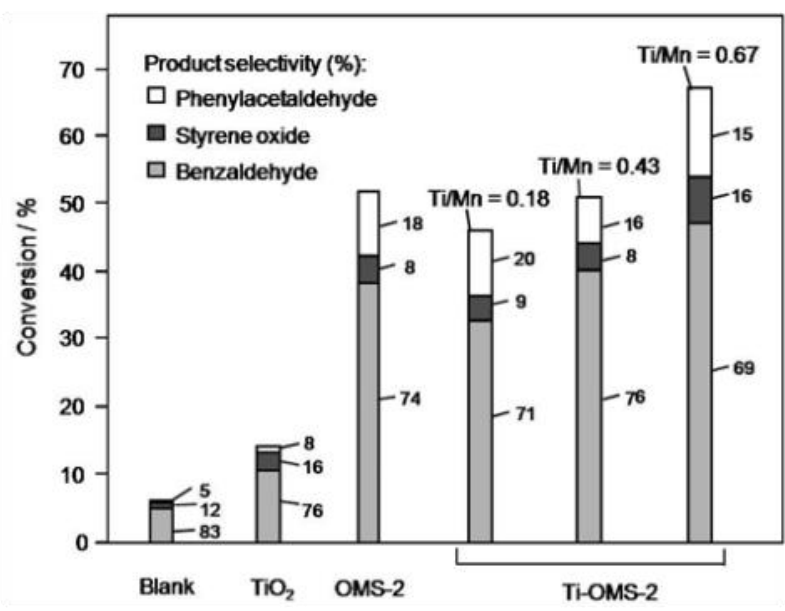

Figure 8 . The conversion and product selectivity of the oxidation of styrene with TBHP using various catalysts 
Table 2. The correlation of Lewis acidity of samples to conversion of cyclohexane, cyclohexene and styrene.

\begin{tabular}{lcccc}
\hline Catalysts & $\begin{array}{c}\text { Lewis acidity } \\
\text { strength }^{\mathrm{a}}\end{array}$ & $\begin{array}{c}\text { Conversion of cyclo- } \\
\text { hexane (\%) }\end{array}$ & $\begin{array}{c}\text { Conversion of cyclo- } \\
\text { hexene (\%) }\end{array}$ & $\begin{array}{c}\text { Conversion of sty- } \\
\text { rene (\%) }\end{array}$ \\
\hline Ti-OMS-2 (0.67) & strong & 7.4 & 65 & 70 \\
OMS-2 & weak & 4.4 & 21 & 52 \\
\hline
\end{tabular}

a The strength of Lewis acidity is relative to each other

Table 3. The possible role of Lewis acids of catalyst in oxidation of cyclohexane, cyclohexene and styrene.

\begin{tabular}{|c|c|c|c|}
\hline $\begin{array}{c}\text { Substrate for oxi- } \\
\text { dation reactions } \\
\text { with aqueous } \mathrm{H}_{2} \mathrm{O}_{2} \\
\end{array}$ & Products & Site activation & Role of Lewis acid sites \\
\hline Cyclohexane & $\begin{array}{c}\text { Cyclohexanone and cyclo- } \\
\text { hexanol }\end{array}$ & C-H & Electron abstraction to form radical \\
\hline Cyclohexene & $\begin{array}{c}2 \text { cyclohexen-1-one, } 2 \text { cyclo- } \\
\text { hexe-1-ol and epoxycyclo- } \\
\text { hexane }\end{array}$ & $\mathrm{C}-\mathrm{H}$ and $\mathrm{C}=\mathrm{C}$ & $\begin{array}{c}\text { Electron abstraction to form radical and } \\
\text { acid-base adduct }\end{array}$ \\
\hline Styrene & $\begin{array}{c}\text { Benzaldehyde, phenyl ac- } \\
\text { etaldehyde and styrene } \\
\text { oxide }\end{array}$ & $\mathrm{C}=\mathrm{C}$ & acid-base adduct \\
\hline
\end{tabular}

hancement of catalytic activity of Ti-OMS-2 material. This was in agreement with Corma and García [36]; that Lewis acids can catalyze oxidation reactions. According to them, there are two possible ways for the Lewis acids to catalyze oxidation reactions which depend on the substrates i.e abstraction of electron and acid-base adduct. The possible role of the Lewis acid sites in enhancing the activity of Ti-OMS-2 in oxidation reactions are summarized in Table 3. It shows that the main products for oxidation of cyclohexane are $\mathrm{C}-\mathrm{H}$ bond activation in which Lewis acidity enhances the catalytic activity via abstraction of electron to form radical in homolytic pathway. In cyclohexene there are two ways in which Lewis acid sites play a role in oxidation reaction that is, electron abstraction and acid-base adduct. However, the selectivity of cyclohexene as shown in Section 3.2.2 indicates that the catalyst is more selective toward 2-cyclohexen-1-one and 2-cyclohexe-1-ol compared to epoxycyclohexane and $\mathrm{C}-\mathrm{H}$ bond activation is preferred than $\mathrm{C}=\mathrm{C}$ bond activation. In the oxidation of styrene, Lewis acid sites can only promote acid-base adduct since only $\mathrm{C}=\mathrm{C}$ bond can be activated and it has no allylic $\mathrm{C}-\mathrm{H}$ bond.

\subsubsection{Effect of Different Location of Ti sites in Ti-OMS-2}

Table 4 summarizes the role of location of $\mathrm{Ti}$ sites to catalytic activity of Ti-OMS-2 in oxidation of cyclohexane, cyclohexene and styrene with TBHP as oxidant. Although OMS-2 itself is active for all reactions, incorporation of titanium in the framework and non-framework of OMS-2 catalyst evidently affect the catalytic activity of OMS-2 materials. For oxidation of cyclohexane and cyclohexene, both Ti sites in framework and non-framework enhanced the catalytic activity of OMS-2 catalysts. However, for oxidation of styrene, only titanium nonframework played a role in the enhancement of catalytic activity of Ti-OMS-2. As mentioned before, the main products of oxidation of cyclohexane and cyclohexene was $\mathrm{C}-\mathrm{H}$ bond activation whereas in oxidation of styrene was $\mathrm{C}=\mathrm{C}$ activation. This suggested that incorporation of $\mathrm{Ti}$ in the framework only enhances the catalytic activity of Ti-OMS-2 for C-H bond activation and not $\mathrm{C}=\mathrm{C}$ bond activation. In contrast, $\mathrm{Ti}$ sites in non-framework were active for both bond activations. 
Table 4. The role of Ti sites location in oxidation reactions. ${ }^{a}$

\begin{tabular}{lcccc}
\hline $\begin{array}{c}\text { Substrate for oxi- } \\
\text { dation reactions } \\
\text { with aqueous } \\
\mathrm{H}_{2} \mathrm{O}_{2}\end{array}$ & OMS-2 & Ti in framework & $\begin{array}{c}\text { Ti in framework } \\
\text { and non- } \\
\text { framework }\end{array}$ & $\begin{array}{c}\text { Ti in non- } \\
\text { framework }\end{array}$ \\
\hline cyclohexane & + & ++ & ++ & not available \\
cyclohexene & + & ++ & +++ & not available \\
styrene & + & not active & ++ & ++ \\
\hline
\end{tabular}

a The relative catalytic activity in the order of: $+<++<+++$

b The location of Ti in OMS-2 has been elucidated by several spectroscopy techniques [21]

\section{Conclusions}

In this study, it was shown that the catalyst with high titanium content [Ti-OMS-2(0.67)] with $\mathrm{Ti}$ sites located in framework and nonframework position is found to be the most active catalyst for the oxidation reaction of cyclohexane, cyclohexene and styrene. This suggests that the superior catalytic activity of the catalyst is due to non-framework Ti site, besides the increasing Lewis acidity by incorporating Ti into the framework. The high catalytic activity exhibited by Ti-modified OMS-2 catalysts makes them promising catalyst for oxidation reactions.

\section{Acknowledgements}

The authors would like to acknowledge the following parties for financial supports: the Ministry of Science, Technology and Innovation Malaysia (MOSTI) through Science Fund and Ministry of Higher Education Malaysia (MOHE) through Fundamental Research Grant Scheme.

\section{References}

[1] Suib, S.L. (1996). Synthesis, Characterization and Catalysis with Microporous Ferrierites, Octahedral Molecular Sieves, and Layered Materials. In S. I. W. H. Chon and S. E. Park (Eds.), Studies in Surface Science and Catalysis. 102: 47-74.

[2] Makwana, V.D., Garces, L.J., Liu, J., Cai, J., Son, Y.-C., Suib, S.L. (2003). Selective Oxidation of Alcohols using Octahedral Molecular Sieves: Influence of Synthesis Method and Property-Activity Relations. Catalysis Today, 85(2-4): 225-233.

[3] Makwana, V.D., Son, Y.-C., Howell, A R., Suib, S. L. (2002). The Role of Lattice Oxygen in Selective Benzyl Alcohol Oxidation Using
OMS-2 Catalyst: A Kinetic and IsotopeLabeling Study. Journal of Catalysis, 210(1): 46-52.

[4] Rebello, J.S., Samant, P.V., Figueiredo, J.L., Fernandes, J.B. (2006). Enhanced Electrocatalytic Activity of Carbon-Supported $\mathrm{MnO}_{\mathrm{x}} / \mathrm{Ru}$ Catalysts for Methanol Oxidation in Fuel Cells. Journal of Power Sources, 153(1): 3640.

[5] Luo, J., Zhang, Q., Huang, A., Suib, S.L. (2000). Total Oxidation of Volatile Organic Compounds with Hydrophobic Cryptomelanetype Octahedral Molecular Sieves. Microporous and Mesoporous Materials, 3536(0): 209-217.

[6] Ghosh, R., Shen, X., Villegas, J.C., Ding, Y., Malinger, K., Suib, S.L. (2006). Role of Manganese Oxide Octahedral Molecular Sieves in Styrene Epoxidation. Journal of Physical Chemistry B, 110(14): 7592-7599.

[7] Ghosh, R., Son, Y.-C., Makwana, V.D., Suib, S.L. (2004). Liquid-Phase Epoxidation of Olefins byManganese Oxide Octahedral Molecular sieves. Journal of Catalysis, 224(2): 288296.

[8] Chen, X., Shen, Y.-F., Suib, S.L., O'Young, C.L. (2002). Characterization of Manganese Oxide Octahedral Molecular Sieve (M-OMS2) Materials with Different Metal Cation Dopants. Chemistry of Materials, 14(2): 940-948.

[9] Suib, S.L. (1998). Microporous Manganese Oxides. Current Opinion in Solid State and Materials Science, 3(1): 63-70.

[10] Krishnan, V.V., Suib, S.L. (1999). Oxidative Dehydrogenation of 1-Butene over Manganese Oxide Octahedral Molecular Sieves. Journal of Catalysis, 184(2): 305-315.

[11] Liu, J., Son, Y.-C., Cai, J., Shen, X., Suib, S.L., Aindow, M. (2003). Size Control, Metal Substitution, and Catalytic Application of Cryptomelane Nanomaterials Prepared Using 
Cross-linking Reagents. Chemistry of Materials, 16(2): 276-285.

[12] Segal, S.R., Suib, S.L., Foland, L. (1997). Decomposition of Pinacyanol Chloride Dye Using Several Manganese Oxide Catalysts. Chemistry of Materials, 9(11): 2526-2532.

[13] Zhou, H., Wang, J.Y., Chen, X., O'Young, C.L., Suib, S.L. (1998). Studies of Oxidative Dehydrogenation of Ethanol over Manganese Oxide Octahedral Molecular Sieve Catalysts. Microporous and Mesoporous Materials, 21(46): 315-324.

[14] Arends, I.W.C.E., Sheldon, R.A. (2001). Activities and Stabilities of Heterogeneous Catalysts in Selective Liquid Phase Oxidations: Recent Developments. Applied Catalysis A: General, 212(1-2): 175-187.

[15] Sheldon, R.A., Arends, I.W C.E., Lempers, H.E.B. (1998). Liquid Phase Oxidation at Metal ions and Complexes in Constrained Environments. Catalysis Today, 41(4): 387-407.

[16] He, J., Xu, W.-p., Evans, D. G., Duan, X., Li, C.-Y. (2001). Role of Pore Size and Surface Properties of Ti-MCM-41 Catalysts in the Hydroxylation of Aromatics in the Liquid Phase. Microporous and Mesoporous Materials, 4445(0): 581-586.

[17] Taramasso, M., Perego, G., Notari, B. (1983). Preparation of Porous Crystalline Synthetic Material Comprised of Silicon and Titanium Oxides. U.S. Patent 4,410,501.

[18] Prasetyoko, D., Ramli, Z., Endud, S., \& Nur, H. (2005). Enhancement of Catalytic Activity of Titanosilicalite-1-Sulfated Zirconia Combination towards Epoxidation of 1-Octene with Aqueous Hydrogen Peroxide. Reaction Kinetics and Catalysis Letters, 86(1): 83-89.

[19] Arata, K., Matsuhashi, H., Hino, M., Nakamura, H. (2003). Synthesis of Solid Superacids and their Activities for Reactions of Alkanes. Catalysis Today, 81(1): 17-30.

[20] De Guzman, R.N., Shen, Y.F., Shaw, B.R., Suib, S.L., O'Young, C.L. (1993). Role of Cyclic Voltammetry in Characterizing Solids: Natural and Synthetic Manganese Oxide Octahedral Molecular Sieves. Chemistry of Materials, 5(10): 1395-1400.

[21] Nur, H., Hayati, F., Hamdan, H. (2007). On the Location of Different Titanium Sites in Ti-OMS-2 and their Catalytic Role in Oxidation of Styrene. Catalysis Communications, 8(12): 2007-2011.

[22] Database of Joint Committee for Powder Diffraction Studies (JPCDS) PDF\# 29,102.

[23] O'Young, C.-L., Sawicki, R.A., Suib, S.L. (1997). Micropore Size Distribution of Octahedral Molecular Sieves (OMS). Microporous
Materials, 11(1-2): 1-8.

[24] Cai, J., Liu, J., Willis, W.S., Suib, S.L. (2001). Framework Doping of Iron in Tunnel Structure Cryptomelane. Chemistry of Materials, 13(7): 2413-2422.

[25] Mayer, J.T., Diebold, U., Madey, T.E., Garfunkel, E. (1995). Titanium and Reduced Titania Overlayers on Titanium Dioxide(110). Journal of Electron Spectroscopy and Related Phenomena, 73(1): 1-11.

[26] Zou, Z.-Q., Meng, M., Guo, L.-H., \& Zha, Y.-Q. (2009). Synthesis and Characterization of $\mathrm{CuO} / \mathrm{Ce}_{1-\mathrm{x}} \mathrm{Ti}_{\mathrm{x}} \mathrm{O}_{2}$ Catalysts used for Lowtemperature CO Oxidation. Journal of Hazardous Materials, 163(2-3): 835-842.

[27] Schuchardt, U., Cardoso, D., Sercheli, R., Pereira, R., da Cruz, R.S., Guerreiro, M.C., Pires, E.L. (2001). Cyclohexane Oxidation Continues to be a Challenge. Applied Catalysis A: General, 211(1): 1-17.

[28] Larsen, R.G., Saladino, A.C., Hunt, T.A., Mann, J.E., Xu, M., Grassian, V.H., Larsen, S.C. (2001). A Kinetic Study of the Thermal and Photochemical Partial Oxidation of Cyclohexane with Molecular Oxygen in Zeolite Y. Journal of Catalysis, 204(2): 440-449.

[29] Tian, P., Liu, Z., Wu, Z., Xu, L., He, Y. (2004). Characterization of Metal-containing Molecular Sieves and their Catalytic Properties in the Selective Oxidation of Cyclohexane. $\mathrm{Ca}$ talysis Today, 93-95: 735-742.

[30] Sawatari, N., Yokota, T., Sakaguchi, S., Ishii, Y. (2001). Alkane Oxidation with Air Catalyzed by Lipophilic N-Hydroxyphthalimides without Any Solvent. The Journal of Organic Chemistry, 66(23): 7889-7891.

[31] Wu, P., Xiong, Z., Loh, K. P., \& Zhao, X. S. (2011). Selective oxidation of cyclohexane over gold nanoparticles supported on mesoporous silica prepared in the presence of thioether functionality. Catalysis Science \& Technology, 1(2), 285-294

[32] Salavati-Niasari, M., Banitaba, S.H. (2003). Alumina-Supported $\mathrm{Mn}$ (II), $\mathrm{Co}(\mathrm{II}), \mathrm{Ni}(\mathrm{II})$ and $\mathrm{Cu}$ (II) bis(2-hydroxyanil)acetylacetone Complexes as Catalysts for the Oxidation of Cyclohexene with tert-butylhydroperoxide. Journal of Molecular Catalysis A: Chemical, 201(1-2): 43-54.

[33] Salavati-Niasari, M. (2005). Nanoscale Microreactor-Encapsulation 14-membered Nickel(II) Hexamethyl Tetraaza: Synthesis, Characterization and Catalytic Activity. Journal of Molecular Catalysis A: Chemical, 229(1-2): 159-164.

[34] Salavati-Niasari, M., Salemi, P., Davar, F. (2005). Oxidation of Cyclohexene with tert- 
butylhydroperoxide and Hydrogen Peroxide Catalysted by $\mathrm{Cu}(\mathrm{II}), \mathrm{Ni}(\mathrm{II}), \mathrm{Co}(\mathrm{II})$ and $\mathrm{Mn}(\mathrm{II})$ Complexes of N,N'-bis-(a-methylsalicylidene)2,2-dimethylpropane-1,3-diamine, Supported on Alumina. Journal of Molecular Catalysis A: Chemical, 238(1-2): 215-222.

[35] Fujihara, K., Izumi, S., Ohno, T., Matsumura, M. (2000). Time-resolved Photoluminescence of Particulate $\mathrm{TiO}_{2}$ Photocatalysts Suspended in Aqueous Solutions. Journal of Photochemistry and Photobiology A: Chemistry, 132(12): 99-104.

[36] Corma, A., García, H. (2002). Lewis Acids as Catalysts in Oxidation Reactions: From Homogeneous to Heterogeneous Systems. Chemical Reviews, 102(10): 3837-3892. 